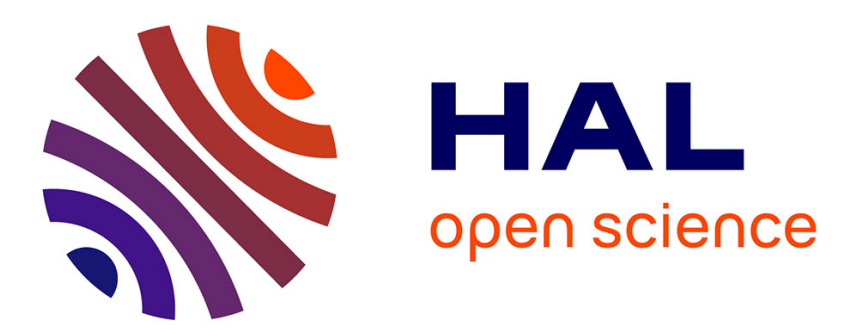

\title{
Coplanar High Impedance Wire on ferrite substrate: Application to isolators
}

Eric Djekounyom, Eric Verney, Didier Vincent

\section{To cite this version:}

Eric Djekounyom, Eric Verney, Didier Vincent. Coplanar High Impedance Wire on ferrite substrate: Application to isolators. IEEE Transactions on Magnetics, 2020, 56 (10), pp.1-5. 10.1109/TMAG.2020.3011634 。 ujm-02904170

\section{HAL Id: ujm-02904170}

\section{https://hal-ujm.archives-ouvertes.fr/ujm-02904170}

Submitted on 13 Aug 2020

HAL is a multi-disciplinary open access archive for the deposit and dissemination of scientific research documents, whether they are published or not. The documents may come from teaching and research institutions in France or abroad, or from public or private research centers.
L'archive ouverte pluridisciplinaire HAL, est destinée au dépôt et à la diffusion de documents scientifiques de niveau recherche, publiés ou non, émanant des établissements d'enseignement et de recherche français ou étrangers, des laboratoires publics ou privés. 


\title{
Coplanar High Impedance Wire on ferrite substrate : Application to isolators
}

\author{
Eric Djekounyom ${ }^{1,2}$, Eric Verney ${ }^{1}$, Didier Vincent ${ }^{1}$ \\ ${ }^{1}$ Univ Lyon, UJM-Saint-Etienne, CNRS, Laboratory Hubert Curien UMR 5516, France \\ ${ }^{2}$ Institut National Supérieur des Sciences et Techniques d'Abéché, Chad
}

\begin{abstract}
This article concerns a structure of high-impedance wires (HIW) based on ferrite substrate coplanar waveguide (CPW). Slotted planar stubs are etched on one or two ground planes of the CPW line. Several prototype measurements have been performed showing excellent performance to implement narrow-band microwave isolators. These HIW components can work at low bias-field giving an easier implementation in microwave devices.
\end{abstract}

Index Terms-High-impedance wire (HIW), defected ground structure (DGS), non-reciprocal component, isolator, coupled slotlines, ferrite substrate, metamaterial, metaline.

\section{INTRODUCTION}

$\mathbf{S}$ EVERAL years ago, some authors [1] have developed metallic electromagnetic structures known as artificial magnetic conductor, or high impedance surface (HIS). The concept of high-impedance wire (HIW) proposed in [2] can be considered as 1-D metamaterial similar to high-impedance "meta-surfaces". HIS and HIW are usually fabricated with resonant structures periodically repeated in order to transform a conventional conductive ground plane into a high-impedance domain avoiding the propagation at resonance frequencies. They are generally modeled as small resonant circuits connected in series.

HISs forbid TM waves, and thus can be used as frequency selective surfaces, but can support TE waves in the form of leaky waves [3] which radiate or "leak" energy continuously when they travel through the surface, as in [26]-[28]. Similarly, in guided mode, several 1-D version of high impedance structures (HIW) were implemented in microstrip or coplanar waveguide (CPW) technology for various applications mainly associated with antenna technology [4]-[7] or low-pass filters [8], [9]. Unlike periodic structures named electromagnetic band gap (EBG) structures which operate at Bragg resonance frequency, high impedance structures, also known as defected ground plane structures operate below Bragg resonance frequency. For those structures, most of the applications presented in literature have a reciprocal behavior since the resonant elements are placed on dielectric substrates. But for applications such as circulators and isolators, magnetic materials and external magnetic bias field are needed to generate the non-reciprocal behavior. Several isolators based on ferromagnetic resonance, Faraday rotation and/or field displacement were developed in waveguide or in planar technology [10]-[20].

However, the miniaturization and the integration of nonreciprocal components still remain a major challenge for the microwave telecommunication industry. In planar technology, M. E. Hines [18] has designed an isolator using a microstrip line with a magnetized ferrite substrate. The non-reciprocal

Manuscript received July 17, 2019. Corresponding author: E. Verney (email: eric.verney@univ-st-etienne.fr). propagation is created by the field displacement phenomenon involving a non-uniform field distribution on each side of the metal strip. On one side is placed an absorber inducing high losses for only one propagation direction. This isolator works in a wide frequency band with low insertion losses.

To go to more compact and integrated components, coplanar structure seems to be more convenient. A narrow-band isolator has been performed using a non-symmetrical CPW on polarized ferrite substrate [10]. The operating frequency is about $10.6 \mathrm{GHz}$, the insertion losses are close to $1 \mathrm{~dB}$ and the isolation is superior to $20 \mathrm{~dB}$. But a strong DC field is applied by a permanent magnet making it difficult to adjust the operating frequency.

In order to increase the operating frequency, other structures, combining HIW and ferrite substrate, have been developed in microstrip technology by J. Wu [19] and R. Guo [20]. Isolations of about $11.5-19 \mathrm{~dB}$ are reached in $\mathrm{Ku}$ band but the insertion losses (greater than $3.5 \mathrm{~dB}$ ) are too high for an industrial exploitation, and a high magnetic bias field is required $(0.5-4 \mathrm{kOe})$. To our knowledge, there is no previous work on structures combining magnetic materials and HIW in coplanar technology for microwave non reciprocal applications, that is the novelty of our design.

In this paper, we propose a novel non-reciprocal microwave component, using the concept of HIW. The structure is performed from a CPW printed on ferrite substrate (yttrium iron garnet). Under low magnetic bias field of about $70 \mathrm{Oe}$, prototypes show isolations better than $55 \mathrm{~dB}$ with a bandwidth at $-20 \mathrm{~dB}$ of $80 \mathrm{MHz}$ and insertion losses lower than $1 \mathrm{~dB}$ at the operating frequency of $13.6 \mathrm{GHz}$. The performance of the proposed structure is at the state of the art of commercial narrow-band isolators.

\section{StRucture AND Design CONSIDERATIONS}

The structure under consideration is depicted in figure (1). The host transmission line is a $4 \mathrm{~mm}$-length $\mathrm{CPW}$, with geometrical parameters designed to achieve a characteristic impedance of $50 \Omega$ and low radiation losses: signal line $S=212 \mu \mathrm{m}$, slot width $W=212 \mu \mathrm{m}$, thickness of YIG 

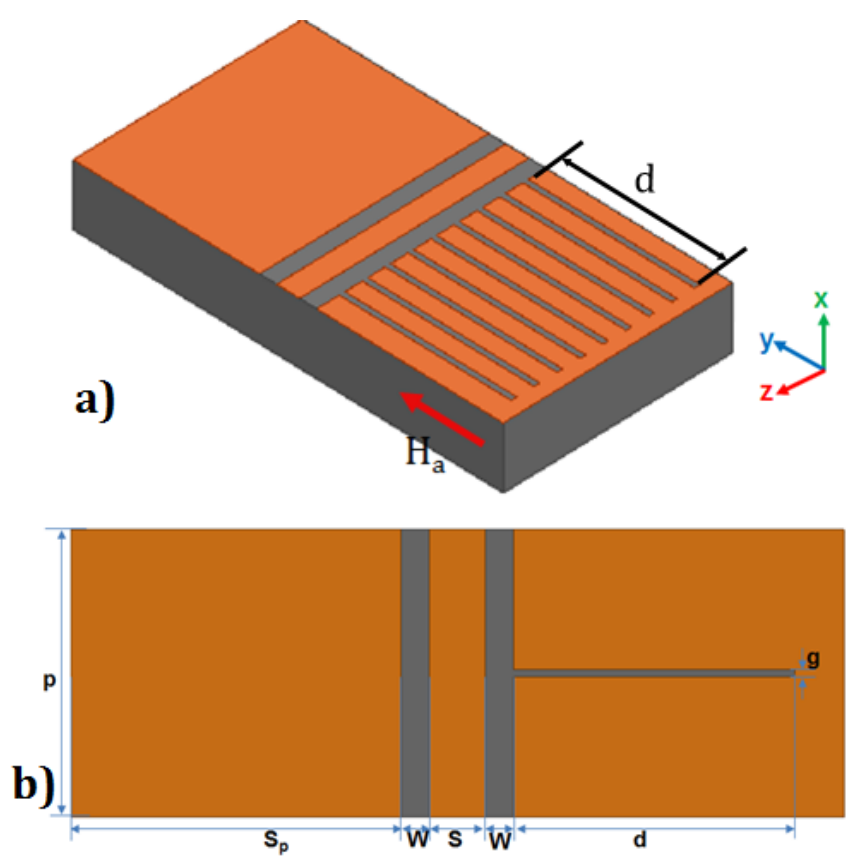

Fig. 1. Design of the structure: a) non-symmetrical configuration of the component, b) geometrical parameters of the initial unit cell: $S=212 \mu \mathrm{m}$, $W=212 \mu \mathrm{m}, W_{p}=5.1 \mathrm{~mm}$, slot width $g=40 \mu \mathrm{m}$, slot length $d=5$ $\mathrm{mm}$, period $p=400 \mu \mathrm{m}$.

substrate $h=1000 \mu \mathrm{m}$, thickness of copper layer, $e=3 \mu \mathrm{m}$ and width of ground plane $S_{p}=5.1 \mathrm{~mm}$. Two configurations are possible for the proposed structure: in the symmetrical configuration the slots are engraved on both ground planes while in non-symmetrical configuration they are etched on one ground (figure 1.a). According to the transmission line model of HIW presented in [2], the impedance provided by the single series stub of the non-symmetrical configuration is higher than that provided by the two stubs connected in parallel of the symmetrical one. In this paper we are interested in the nonsymmetrical version since we are looking for the higher value of the impedance of the stubs in order to produce stronger resonances.

\section{A. Design of the HIW structure}

HIWs are defined by three design parameters [2]: the period of the unit cell $p$, the length of the stub $d$, and the width of the slot $g$. A theoretical analysis of this kind of structure and the design procedure have been widely developed in [24] and [25]. Following this procedure HIWs were designed for applications in microwave in previous works [26]-[28]. Due to the complexity of the structures, which involves strong coupling between the slots, as anisotropic nature of the substrate, quasistatic equations are not enough accurate, so electromagnetic simulations using finite elements softwares are usually needed to perform the accurate values of the design parameters.

The first step is to design the unit cell of the resonant circuit shown in (figure 1.b). The equations giving the approximate values of the geometrical parameters of the unit cell can be found in [24] and [25]: the width of the slot, $g$, was set to $40 \mu \mathrm{m}$ much smaller than $\lambda_{g}$, so that the slot can be treated as a series stub, and the length of slot, $d=5000 \mu \mathrm{m}$, was tailored to achieve the first resonance frequency $f_{r}$ at $5 \mathrm{GHz}$ corresponding to $\lambda_{g} / 4$ on a YIG substrate with a dielectric constant $\epsilon_{r}=15.3$. According to the equation (1) [2] which approximately gives the dimensional resonant frequencies, the second resonance $(m=1)$ will occur in Ku-band, around 15 GHz:

$$
f_{r} \approx(2 m+1) \frac{c}{4 d \sqrt{\varepsilon_{e f f} \mu_{e f f}}}
$$

with $m=0,1,2,3, \ldots, c$ the speed of light in vacuum, $\epsilon_{e f f}$ and $\mu_{e f f}$ respectively the effective permittivity and permeability on the slotline stubs.

To remain in the theoretical case of HIW and a metamaterial viewpoint, the length of the unit cell, known as the period $p$ of the HIW, must be smaller than length of slot $d$. On the other hand, $p$ is usually chosen as large as possible to avoid strong coupling between the slots and simplify the analysis of the structure. However, this constraint leads to large structures, and we wish to make a device as compact as possible. Anyway, coupling between slotlines on an axially magnetized ferrite as been treated in [29], leading to theoretically describe the coupling in a HIW. So, in our case the period $p$ was set to $400 \mu \mathrm{m}$ to ensure compactness of the structure. The global resonance frequency of the unit cell is of type LC, with the inductive part brought by the resonating stub, and the capacitive one by the parasitic capacitance between the coupled stubs. To adjust the operating frequency of the isolator one has thus the choice to modulate the effect of the parasitic capacitance, which increase as $p$ shortens, by lengthen the size of the isolated stub. To fix the number of stubs, following the procedure in [7], we add unit cells to the structure until the performance criteria are reached. With the given values of $p, d$ and $g, 9$ stubs and static magnetic field $H_{a}=70$ Oe, by simulation, two resonance frequencies are obtained at 13.7 $\mathrm{GHz}$ for the forward propagation and $15.2 \mathrm{GHz}$ for the backward propagation (Fig. 4).

\section{B. Magnetic field distribution on the defected ground plane}

As mentioned in [19] the analytic close form distribution equations for the defected ground plane structure can be complicated. To analyze the magnetic field distribution, the Ansoft HFSS full wave simulator has been used. For the original ground plane, the current flows mainly on the edge along $z$ axis and the magnetic field distribution is dominated by the components $H_{x}$ and $H_{y}$. Whereas for the DGS the presence of slots forces the current flowing around the new edges as schematically presented in figure 2.a. This leads to rotating magnetic field with components $H_{x}$ and $H_{z}$ [19], [20], [29]. When an in-plane DC magnetic bias is applied along $y$-axis the magnetic field around the coupled slots is characterized by Right-Handed Circular Polarization (RHCP) for forward input (figure 2.b) and a Left-Handed Circular Polarization (LHCP) for backward input (figure 2.c). Then the propagation constant in the stubs takes two different values, depending on the direction of propagation. According to [29], even and odd modes in the parallel slots are coupled, and RHCP and LHCP propagation constants can be express as a 
a)

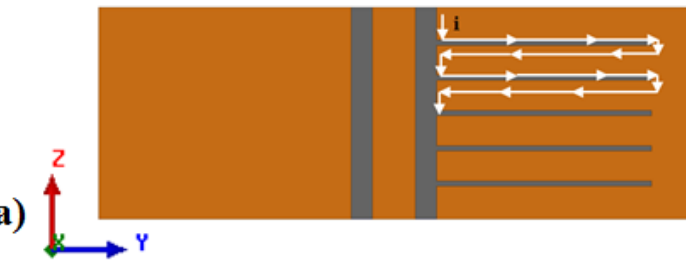

Forward input

Port 1 to port 2

b)

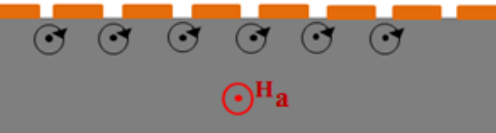

c)

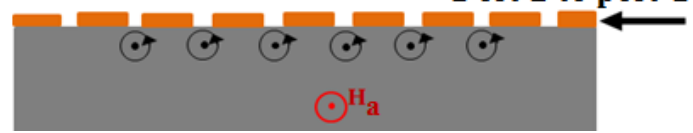

Fig. 2. Configuration of magnetic field on the defected ground plane: a) direction of current, b) RHCP for forward transmission, b) LHCP for backward transmission.

function of $\beta_{\text {even }}$ and $\beta_{\text {odd }}$ and a coupling coefficient $C$ caused by the gyrotropy of the ferrite as shown in equation (2) [29].

$$
\beta_{R H C P}, \beta_{L H C P}=\left(\frac{\beta_{\text {even }}+\beta_{\text {odd }}}{2}\right) \pm \sqrt{\Delta \beta^{2}+\left|C^{2}\right|}
$$

with $\Delta \beta=\frac{\beta_{\text {even }}-\beta_{\text {odd }}}{2}$ and $C$ depending on an integral of $H$ fields over the cross-section of the substrate [29].

This behavior of coupled slots on an axially magnetized ferrite slab leads to non reciprocal resonance frequencies of the HIW, as shown in figure 4 and theoretically detailed in [30], and quantitatively explains the difference between the two resonance frequencies. Using the coupled-mode theory, the authors develop in the reference [30] the theory on the coupling in symmetrical structures when the ferrite is magnetized in the Faraday model similar to the isolator structure under consideration.

Finally, as demonstrated in previous works, the metallization thickness effect produces a slight non-reciprocity in CPWs with ferrites magnetized in the plane of the slab because of the difference of the field distribution between the backward and forward waves [23]. The contribution of this second source added to the effects of circular polarizations thus leads to a non-reciprocal structure.

\section{EXPERIMENTAL RESULT AND DISCUSSIONS}

\section{A. Manufacture of the structure}

The fabricated prototypes are shown in figure 3. The 1000 $\mu \mathrm{m}$-thick substrate is obtained by thinning a bulk YIG (Temex Ceramics) whose properties are given in table I. The surface of the substrate was then grinded and polished in order to reduce his roughness and thus improve the homogeneity of the copper layer that will be deposited by $R F$ sputtering. The thickness of the copper ground planes and signal line is around $3 \mu \mathrm{m}$. The coplanar transmission line and the stub network on
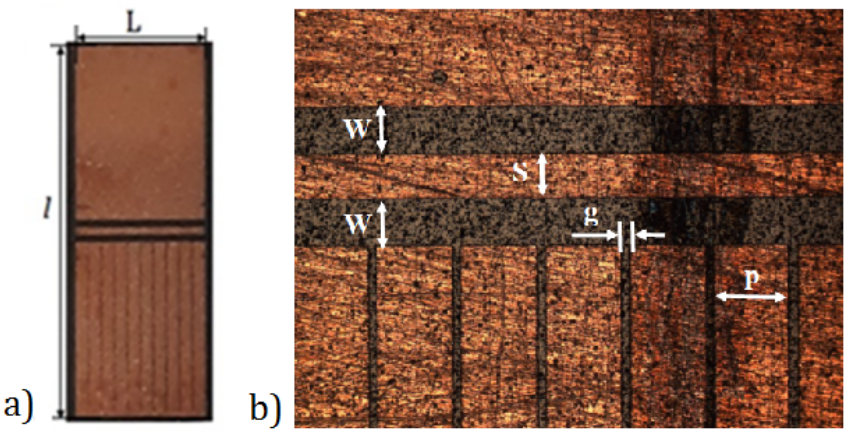

Fig. 3. Prototype of coplanar HIW isolator: a) photograph of prototype with 9 slots, $l=11 \mathrm{~mm}$ and $L=4 \mathrm{~mm}$, b) geometrical parameters measured with optical microscope: $S=212 \mu \mathrm{m}, W=220 \mu \mathrm{m}$, slot width $g=40 \mu \mathrm{m}$, slot length $d=5 \mathrm{~mm}$ and period $p=400 \mu \mathrm{m}$.

TABLE I

Magnetic Properties of Yig SUbSTRates.

\begin{tabular}{|c|c|c|c|c|c|c|}
\hline Reference & $\begin{array}{c}\mu_{0} \mathrm{Ms} \\
(\mathrm{mT}) \\
\pm 5 \%\end{array}$ & $\begin{array}{c}\Delta \mathrm{H} \\
(\mathrm{A} / \mathrm{m}) \\
\pm 5 \%\end{array}$ & $\begin{array}{c}\epsilon_{r} \\
\pm 5 \%\end{array}$ & $\tan \delta$ & $\begin{array}{c}T_{c} \\
\left({ }^{\circ} \mathrm{C}\right) \\
\pm 5 \%\end{array}$ & $\begin{array}{c}H_{C} \\
(\mathrm{~A} / \mathrm{m}) \\
\pm 5 \%\end{array}$ \\
\hline YIG 101 & 182 & 1590 & 15.4 & $<2.10^{-4}$ & 280 & $<100$ \\
\hline
\end{tabular}

the ground plane are made by conventional photolithography processes. Several prototypes were then characterized under low-bias DC magnetic field with a vector network analyzer (A37397 Anritsu) and a coplanar probes system. The magnetic bias field $(70 \mathrm{Oe})$ can be produced either by an electromagnet or a permanent magnet, and is applied along the stubs during the S-parameters measurement. According to the applied field configuration (transverse polarization), the demagnetization field is negligible and for low bias-field (over $60 \mathrm{Oe}$ ) the YIG can be considered in the saturated state, since the YIG is magnetized in the plane, we can say that it is near saturation state in agreement with the measurement made in [31]. That constitutes a great advantage compared to other structures requiring high bias field.

\section{B. Results and discussions}

For the applied magnetic bias field of about $H_{a}=70 \mathrm{Oe}$, the measured and simulated S-parameters shown in figure 4 confirm the non-reciprocal propagation on the structure. For the forward propagation, the isolation is better than $55 \mathrm{~dB}$ at 13.6 GHz, with the insertion losses lower than $1 \mathrm{~dB}$ (around $0.8 \mathrm{~dB}$ ) and the reflection parameters are lower than $-20 \mathrm{~dB}$, which proves that the missing energy is not reflected back to the port 1. However, the narrow isolation peak leads to small bandwidth of $80 \mathrm{MHz}$ at $-20 \mathrm{~dB}$. In the reverse direction, the isolation peak appears around $15.2 \mathrm{GHz}$ but does not reach $10 \mathrm{~dB}$. The return and insertion losses are respectively about 8 and $5 \mathrm{~dB}$ with, notwithstanding, a wider bandwidth. Good agreement between simulation and measurement is observed for the resonance frequencies, with a slight shift of $0.1 \mathrm{GHz}$. However, the performance related to amplitudes is better in measurement than in simulation. This difference in amplitudes can be explained by the magnetization conditions 


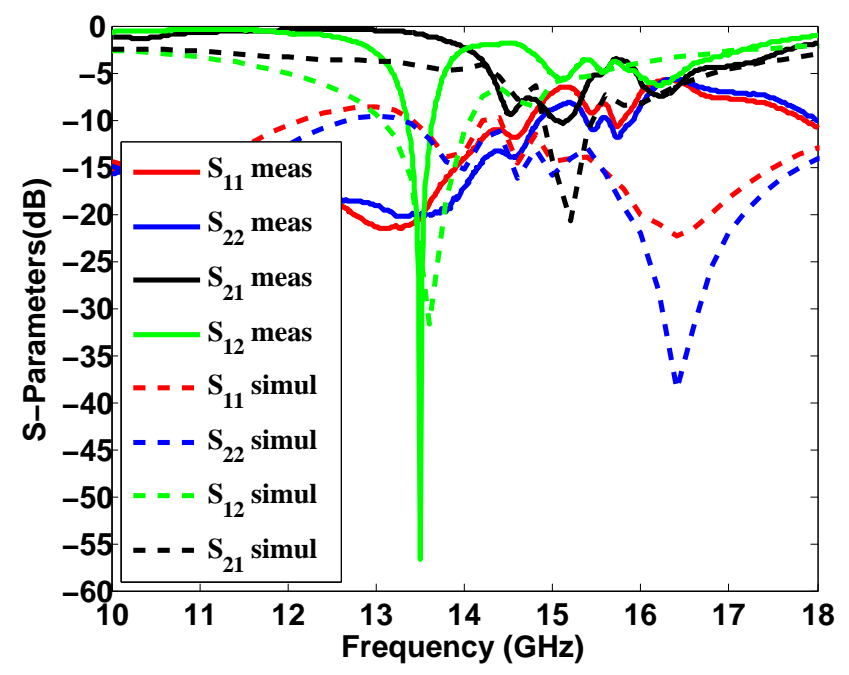

Fig. 4. S-parameters of the structure with 9 stubs under a magnetic bias field $H_{a}=70$ Oe. Solid curve: measurement, dashed curve: simulation.

of the ferrite. Indeed, the simulations consider that the internal magnetic field is constant and the material saturated in all the material, whereas in measurement the internal DC field is inhomogeneous [32]. For better accuracy, the static magnetization state of the slab could be first simulated and integrated in the dynamic simulation.

This structure can be used as simple narrow-band isolator showing high performance. A comparison among different isolators given in table II confirms the performance of our design. The power budget shows strong losses at resonance frequencies. As operating frequencies are far from the gyroresonance of the ferrite, the main origin of losses can not be magnetic. A prototype fabricated on alumina showed the same behavior as the non magnetized HIW-CPW on ferrite, as shown in figure 5, which indicates that losses are coming from the metallic structure. Losses could be due to leaky waves propagating on the DGS. Under bias field, HFSS simulations show that the structure is radiating, as it can be seen on figure 6. In this simulation the HIW-CPW is in the $Y Z$ plane, with signal flowing along $z$-axis. The radiation pattern of the structure has strong similarities with that of a leaky wave antenna. Further measurements in an anechoic room should confirm these simulation results.

\section{CONCLUSION}

In summary, a non-reciprocal microwave device with a coplanar defected ground transmission line based on a ferrite substrate has been designed, fabricated, and measured under DC magnetic field. With 70 Oe magnetic bias field, prototypes show good performance to implement a narrow-band tunable isolator: isolation better than $55 \mathrm{~dB}$ with a bandwidth at -20 $\mathrm{dB}$ of $80 \mathrm{MHz}$ and insertion loss of about $0.8 \mathrm{~dB}$ at 13.6 $\mathrm{GHz}$. Since a low bias magnetic field is required, the use of a small magnet or a small coil is therefore possible. Accordingly, the operating frequency can be controlled by switching the direction of the bias-field, allowing the concept of switched
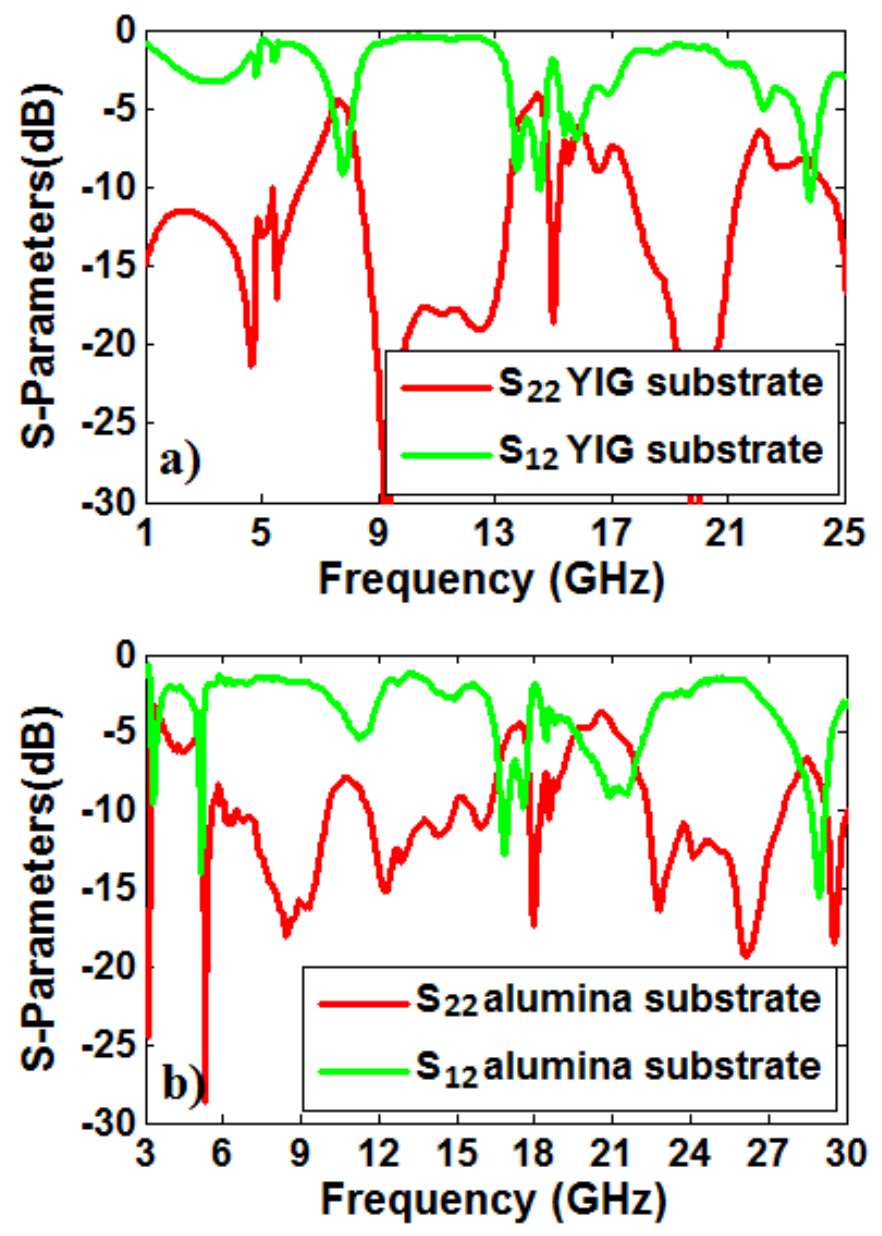

Fig. 5. Measured S-parameters of the HIW-CPW: a) on demagnetized YIG, b) on alumina substrate.

dual passive filters. At the operating frequency the missing energy seems to be radiated as in leaky waves antennas, giving the possibility to put absorbents outside the structure. Other experimental works are under consideration to widen the bandwidth of the isolator and make it tunable, as well as to quantify the radiated energy, which may allow the use of the structure as an dual-band antenna.

\section{REFERENCES}

[1] D. Sievenpiper, L. Zhang, R. F. J. Broas, N. G. Alexopolous, and E. Yablonovitch, "High-impedance electromagnetic surfaces with a forbidden frequency band", IEEE Trans. Microw. Theory Tech., vol. 47, no 11, p. 2059-2074, Nov. 1999.

[2] A. M. Safwat, S. A. Tretyakov, and A. V. Raisanen, "High-impedance wire", IEEE Antennas Wirel. Propag. Lett., vol. 6, p. 631-634, 2007.

[3] F. Monticone and A. Alu, "Leaky-Wave Theory, Techniques, and Applications: From Microwaves to Visible Frequencies", Proc. IEEE, vol. 103, no 5, p. 793-821, May 2015.

[4] Dale Stevens and al., "A periodically perturbed coplanar wave guide transmission line leaky wave antenna", IEEE Antennas and Propagation Society International Symposium, p. 465-468, 2007.

[5] Tzung-Fang Huang, Shih-Wen Lu, and Powen Hsu, "Analysis and design of coplanar waveguide-fed slot antenna array", IEEE Trans. Antennas Propag., vol. 47, no 10, p. 1560-1565, Oct. 1999.

[6] D. Sievenpiper, J. Schaffner, J. J. Lee, and S. Livingston, "A steerable leaky-wave antenna using a tunable impedance ground plane", IEEE Antennas Wirel. Propag. Lett., vol. 1, p. 179-182, 2002. 
TABLE II

COMPARISON OF THE PERFORMANCE OF OUR STRUCTURE AND OTHERS DESIGNS FOUND IN THE RECENT LITERATURE.

\begin{tabular}{llllllll}
\hline $\begin{array}{l}\text { Reference work, } \\
\text { year }\end{array}$ & $\begin{array}{l}\text { Operating frequency } \\
(\mathrm{GHz})\end{array}$ & $\begin{array}{l}\text { Isolation } \\
(\mathrm{dB})\end{array}$ & $\begin{array}{l}\text { Insertion loss } \\
(\mathrm{dB})\end{array}$ & $\begin{array}{l}\text { Applied field } \\
(\mathrm{Oe})\end{array}$ & $\begin{array}{l}\text { Size } \\
\left(\mathrm{mm}^{2}\right)\end{array}$ & Ferrite & Technology \\
\hline This work & 13.6 & 57 & 0.8 & 70 & $11 \times 4$ & YIG & HIW-CPW \\
\hline$[20], 2018$ & 17.57 & 11.6 & 5.78 & 3500 & - & NiZn & HIW-Microstrip \\
\hline$[16], 2014$ & $9.81-10.24$ & $30-55$ & $1.1-2.2$ & 2630 & $22.6 \times 8$ & YIG & SIW \\
\hline$[15], 2013$ & $13.5-16$ & $17-30$ & $2-5$ & 4000 & $\approx 39.2 \times 12$ & YIG & SIW \\
\hline$[19], 2012$ & 13.5 & 19.3 & 3.5 & 4000 & $\approx 22 \times 9$ & YIG & HIW-Microstrip \\
\hline$[10], 2011$ & 10.6 & 17 & 1 & 2260 & $10 \times 4$ & YIG & CPW \\
\hline
\end{tabular}

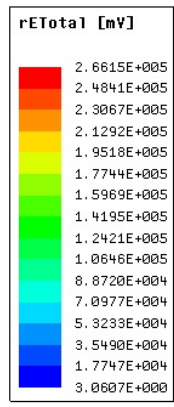

a)

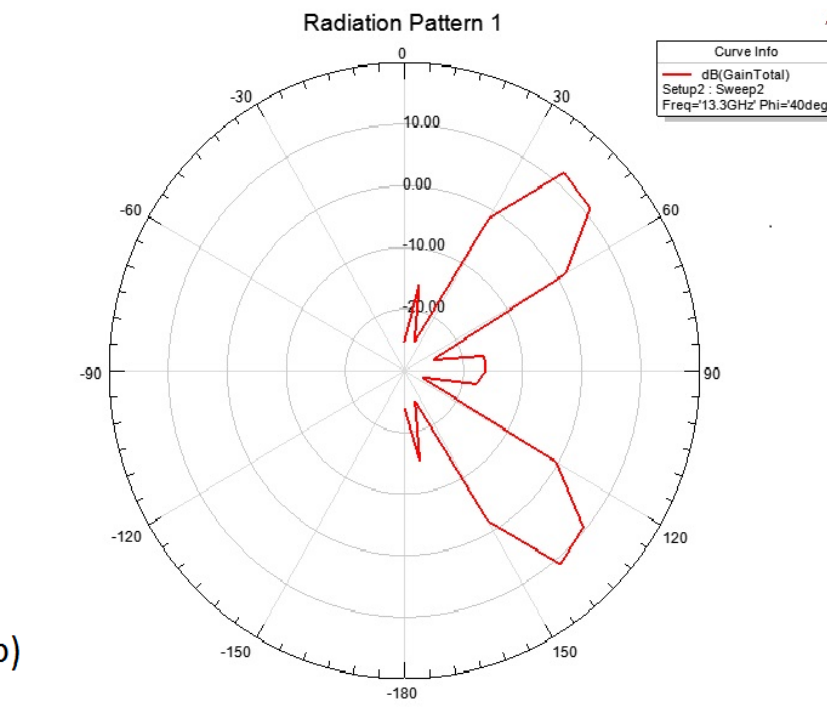

Fig. 6. Radiation pattern of the polarized HIW-CPW at the resonance frequency. a) 3D polar plot of total $\mathrm{E}$ field. b) Total gain in $\mathrm{dB}$ of the radiation pattern in the plane $\phi=40^{\circ}$.

[7] A. Grbic and G. V. Eleftheriades, "Leaky CPW-based slot antenna arrays for millimeter-wave applications", IEEE Trans. Antennas Propag., vol. 50, no 11, p. 1494-1504, Nov. 2002.

[8] D. Ahn, J.-S. Park, C.-S. Kim, J. Kim, Y. Qian, and T. Itoh, "A design of the low-pass filter using the novel microstrip defected ground structure", IEEE Trans. Microw. Theory Tech., vol. 49, no 1, p. 86-93, Jan. 2001.

[9] S. J. Kim and N. H. Myung, "A new PBG structure : Corrugated CPW", Microw. Opt. Technol. Lett., p. 412-414, 2003.

[10] S. Kirouane, D. Vincent, E. Verney, O. Zahwe, B. Payet-Gervy, and A. Chaabi, "Design of a new coplanar isolator made from YIG film operating in the X-frequency band", Eur. Phys. J. - Appl. Phys., vol. 57, no 1 , Jan. 2012

[11] C. P. Wen, "Coplanar Waveguide: A Surface Strip Transmission Line
Suitable for Nonreciprocal Gyromagnetic Device Applications", IEEE Trans. Microw. Theory Tech., vol. 17, no 12, p. 1087-1090, 1969.

[12] B. Bayard, D. Vincent, C. R. Simovski, and G. Noyel, "Electromagnetic study of a ferrite coplanar isolator suitable for integration", IEEE Trans. Microw. Theory Tech., vol. 51, no 7, p. 1809-1814, 2003.

[13] J. J. Kostelnick, "Field displacement isolator", US Patent 3035 235, 1962.

[14] H. S. Skulason and al., "Field effect tuning of microwave Faraday rotation and isolation with large-area graphene", Appl. Phys. Lett., vol. 107, no 9, p. 093106, 2015.

[15] K. Wu, C. Akyel, and F. Fesharaki, "Broadband substrate integrated waveguide edge-guided mode isolator", Electron. Lett., vol. 49, no 4, p. 269-271, Feb. 2013.

[16] Y. J. Cheng, Q. D. Huang, Y. R. Wang, and J. L.-W. Li, "Narrowband substrate integrated waveguide isolators", IEEE Microw. Wirel. Compon. Lett., vol. 24, no 10, p. 698-700, 2014.

[17] T. M. F. Elshafiey, J. T. Aberle, and E.-B. El-Sharawy, "Full wave analysis of edge-guided mode microstrip isolator", IEEE Trans. Microw. Theory Tech., vol. 44, no 12, p. 2661-2668, 1996.

[18] M. E. Hines, "Reciprocal and Nonreciprocal Modes of Propagation in Ferrite Stripline and Microstrip Devices", IEEE Trans. Microw. Theory Tech., vol. 19, no 5, p. 442-451, 1971.

[19] J. Wu, M. Li, X. Yang, S. Beguhn, and N. X. Sun, ”A Novel Tunable Planar Isolator with Serrated Microstrip Structure", IEEE Trans. Magn., vol. 48, no 11, p. 4371-4374, 2012.

[20] R. Guo and al., "An integrated tunable isolator based on NiZn film fabricated by spin-spray plating", AIP Adv., vol. 8, no 5, p. 056620 , 2018.

[21] A. M. E. Safwat, "High impedance wire composite right/left-handed transmission lines", Microw. Opt. Technol. Lett., vol. 52, no 6, p. 1390-1393, 2010.

[22] N. I. Dib, W. P. Harokopus, G. E. Ponchak, and L. P. B. Katehi, "A comparative study between shielded and open coplanar waveguide discontinuities", Int. J. Microw. Millim.-Wave Comput.-Aided Eng., vol. 2, no 4, p. 331-341, 1992.

[23] T. Kitazawa and T. Itoh, "Asymmetrical coplanar waveguide with finite metallization thickness containing anisotropic media", IEEE Trans. Microw. Theory Tech., vol. 39, no. 8, pp. 1426-1433, Aug. 1991.

[24] L. Martín-Moreno, F. J. García-Vidal, H. J. Lezec, A. Degiron, and T.W. Ebbesen, "Theory of highly directional emission from a single subwavelength aperture surrounded by surface corrugations", Phys. Rev. Lett., vol. 90, p. 167 401, Apr. 2003.

[25] F. J-García-Vidal, H. J. Lezec, T. W. Ebbesen, and L. MartínMoreno,"Multiple paths to enhance optical transmission through a single subwavelength slit", Phys. Rev. Lett., vol. 90, p. 213901, May 2003.

[26] M. Beruete, I. Campillo, J. S. Dolado, J. E. Rodríguez-Seco, E. Perea, and M. Sorolla, "Enhanced microwave transmission and beaming using a subwavelength slot in corrugated plate", IEEE Antennas Wirel. Propag. Lett., vol. 3, no. 16, pp. 328-331, 2004.

[27] M. B. Díaz et al., "Dual-band low-profile corrugated feeder antenna", IEEE Trans. Antennas Propag., vol. 54, no. 2, pp. 340-350, 2006.

[28] A. Sutinjo and M. Okoniewski, "A simple leaky-wave analysis of 1-D grooved metal structure for enhanced microwave radiation", IEEE Trans. Antennas Propag., vol. 60, no. 6, pp. 2719-2726, 2012.

[29] C.S. Teoh and L. E. Davis, "Normal-mode analysis of ferrite-coupled lines using microstrips or slotlines", IEEE Trans. Microw. Theory Tech., vol. 43, no. 12, pp. 2991-2998, Dec. 1995. 
[30] J. Mazur and M. Mrozowski, "On the mode coupling in longitudinally magnetized waveguide structure", IEEE Trans. Microw. Theory Tech., vol 37, n 1, Jan. 1989.

[31] E. Schlömann and T. Kohane, "HighField Magnetization Curve of Porous Polycrystalline YIG", J. Appl. Phys., vol. 38, no. 3, pp. 11181120, 1967.

[32] V.VK Thalakkatukalathil and al., "Electromagnetic modeling of anisotropic ferrites-Application to microstrip Y-junction circulator design”, J. Appl. Phys., vol. 123, no. 23, p. 234503, 2018. 